BOOK REVIEW

\title{
Henry A. Giroux, The Terror of Neoliberalism: Authoritarianism and the Eclipse of Democracy. Aurora: Garamond Press, 2004, 192 pp., \$22.95 paper.
}

\author{
Reviewed by Elaine Coburn, L'École des Hautes Études \\ en Science Sociales.
}

In his book, Giroux makes three central related arguments. His first point is theoretical or methodological. Culture, as much as the material relations of production, is necessary to the reproduction of existing market societies. Ideology matters and is, indeed, an essential component of the reproduction of neoliberal forms of capitalism. Serious scholars of capitalism must take what Gramsci might have called 'ideological materials' - the press, but also, even especially, the education system, churches, prisons - seriously as objects of study, since these are sites of capitalism's reproduction and so also, potentially, sites of resistance. Giroux's second point is mainly descriptive and turns on his argument that the most accurate characterization of the ideological superstructure and politics in the United States today is "proto-fascist", authoritarian - in a word, "totalitarianism lite" (155). Steeped in religious fundamentalism, manipulating fear and restricting basic freedoms in the name of a new kind of "patriotic correctness" (19), the United States is profoundly dangerous, the "anti-liberal, anti-democratic, and anti-socialistic" product of "failed democracy" (15). In short, the United States today is not entirely unlike Nazi Germany if, Giroux hastens to add, differing from the German case in historically specific, nontrivial ways. Giroux's third and final major argument, this time in a normative strain, insists on the privileged role that intellectuals must assume in the struggle over proto-fascist forms of capitalism. Intellectuals are the acknowledged experts, as both interpreters and actors, in the cultural realm that is, in Giroux's view, so fundamentally relevant to politics. By engaging in 'worldly' scholarship, that is, by undertaking research, writing and teaching in ways that are at once rigorous and resolutely, critically 'engaged' with contemporary problems (racism, poverty, etc.) intellectuals can hope to alter the cultural landscape. In so 
doing, they throw a wrench into the workings of a new authoritarian political culture that is never simply superstructural but rather essential to the ongoing reproduction of authoritarianism. This last, normative point follows from Giroux's first, theoretical claim: if authoritarianism is partly about specific political cultures, successfully challenging authoritarianism depends in no small part upon the development of an (imaginative?) democratic discourse and political action.

Much of the book is devoted to developing these three central related arguments in greater detail. Indeed, Giroux's book is an example of the sorts of subjects and approach that an 'engaged intellectual' might take, inside the classroom and also, presumably, in original research. Take one of Giroux's major themes: 'neoliberal racism.' Giroux argues that racism in the United States is manifest in both 'old' and 'new' or neoliberal forms. These forms are related: the repudiation of 'old' forms of racism - meaning overt claims of white racial superiority and the like - goes hand-in-hand with new neoliberal claims to racial 'neutrality' in which failure and success cannot be analysed sociologically, but only in terms of individual responsibility. This makes invisible the link between 'biography and history', to use C.W. Mill's celebrated phrase, so that whites suddenly become responsible for their 'successes' and African-Americans for their 'failures'. At worst, this argument, which privatizes responsibility for success and failure, is recast into a collectivist frame that blames existing racial inequalities in the United States on an African American culture that does not prioritize the values (competition, education, hard work) that are supposedly linked to worldly success. For racial minorities, as with other 'subaltern publics' (to borrow, again, from Gramsci), the consequence is that a social critique of inequality is simply impossible - in a world of neoliberal authoritarianism, the individual is profoundly responsible with the market arbitrating among private persons who fail or succeed based on personal characteristics. Where does the 'authoritarian' in neoliberal 'authoritarianism' come in, at least where race is concerned? Well, those - disproportionately poor, minority youth - who are judged to have failed (due to their deficient personal qualities) are increasingly criminalized for this failure, not least via school systems which increasingly turn over 'problem kids' to the criminal justice system. Giroux's task, as a publicly engaged intellectual is to thus unmask and make visible the ways in social inequalities (racial and otherwise) are translated into privatized understandings of 'success' and (criminal) 'failure'.

Clearly, Giroux's book has much to offer to those interested in political economy of a broadly 'progressive' persuasion. And yet, there are at least three major shortcomings to the book. First, the text reads more like an extended, impassioned journalistic article than scholarship. There is virtually no first-hand research evidence, but rather a long pastiche of quotes and statistics, often from newspaper articles rather than scholarly sources. Readers should expect a long essay, not scholarship - and not even an especially long or 
useful list of secondary scholarly resources. Second, Giroux's writing is rather tortured, perhaps because he wants to say too much. One of Giroux's typically long sentences, regarding the multiple implications of neoliberal racism:

Not only does neoliberalism in this instance empty the public treasury, hollow out public services and limit the vocabulary and imagery available to recognize anti-democratic forms of power and narrow models of individual agency, it also undermines the socially discursive translating functions of any viable democracy by undercutting the ability of individuals to engage in the continuous translation between public considerations and private interests by collapsing the public into the realm of the private (76).

This convoluted prose is rather tiring after a few pages. Furthermore, his writing is interspersed with what might best be described as an unusual use of quotations. For example, Giroux cites Bourdieu as saying we need "to invent another kind of state" (77), a remark so general that, as with many of his citations, you wonder why he insists on the quotation in the first place. Lastly, the author calls out for us "to take back this country" (155) - meaning the United States. With this emphasis on the American situation, I believe that the usefulness of this book is limited within a Canadian classroom. 